\title{
The spectrum of microvascular ultrastructural changes in the subpopulation of patients with migraine and cerebral white matter hyperintensities on MRI
}

\author{
Dorota Dziewulska ${ }^{1}$, Eliza Lewandowska², Izabela Domitrz ${ }^{3}$, Albert Acewicz ${ }^{2}$ \\ ${ }^{1}$ Department of Neurology, Faculty of Medicine, Medical University of Warsaw, Warsaw, Poland, ${ }^{2}$ Department of Neuropathology, \\ Institute of Psychiatry and Neurology, Warsaw, Poland, ${ }^{3}$ Department of Neurology, Faculty of Medical Sciences, Medical University \\ of Warsaw, Warsaw, Poland
}

\begin{abstract}
Aim of the study: Migraine is considered not only as a separate clinical entity but also as a symptom of various brain disorders, including cerebral small vessel diseases. Since cerebral small vessel diseases are usually general angiopathies, evaluation of biopsy material other than brain tissue may help in their diagnosis in vivo. In patients with migraine, brain magnetic resonance imaging (MRI) often shows hyperintense changes in the cerebral white matter. Such changes may indicate the symptomatic nature of migraine and coexisting structural or biochemical vascular abnormalities.

Material and methods: To verify the hypothesis of the symptomatic nature of migraine in patients with abnormal brain neuroimaging, we performed an ultrastructural examination of skin and skeletal muscle vessels in biopsy material from 40 patients with clinically diagnosed migraine and hyperintense white matter lesions on MRI.

Results: In $80 \%$ of the examined patients, ultrastructural examination showed various pathological changes in the microvessels including abnormalities characteristic of cerebral autosomal dominant arteriopathy with subcortical infarcts and leukoencephalopathy (CADASIL) and elastin disorders, as well as less specific changes such as thickening of the basal lamina, narrowing of the vessel lumen, degeneration of the vessel wall cells, endothelial activation, oncosis-like changes, and the presence of various types of deposits in the vessel wall. In 20\% of the examined cases, ultrastructural examination of the vessels was normal.

Conclusions: Patients with migraine and hyperintense cerebral white matter changes on MRI have an increased risk of concomitant microangiopathy. In this group of patients, skin-muscle biopsy allows the identification of cases with coexisting vessel abnormalities.
\end{abstract}

Key words: cerebral small vessel disease, microangiopathy, migraine, skin-muscle biopsy.

\section{Introduction}

Many epidemiological studies suggest that migraine is associated with disorders of the cerebral, coronary, retinal, dermal, and peripheral vasculature. Migraine correlates with a higher risk for myocardial infarction and ischaemic stroke [4], and is one of the prominent features of some genetic cerebral small vessel diseases including cerebral autosomal dominant arteriopathy with subcortical infarcts and leukoencephalopathy (CADASIL), retinal vasculopathy with cerebral leukodystrophy (RVCL), hereditary infantile hemiparesis, 
retinal arteriolar tortuosity and leukoencephalopathy (HIHRATL), or the recently discovered cathepsin-A-related arteriopathy with strokes and leukoencephalopathy (CARASAL) $[10,18]$. Migraine is also a common symptom of mitochondrial diseases such as Leigh-syndrome, Alpers-Huttenlocher disease, MELAS (mitochondrial encephalopathy, lactic acidosis, and stroke-like episodes) syndrome, MERRF (myoclonic epilepsy with ragged red fibres) syndrome, mitochondrial recessive ataxia syndrome, chronic progressive external ophthalmoplegia (CPEO), and others (references in [11]). Because many diseases of small cerebral vessels are generalized angiopathies, introducing skin or skeletal muscle biopsy into their diagnostics allows their early detection.

In brain magnetic resonance imaging (MRI) scans of migraineurs, cerebral white matter often shows hyperintense changes in the T2-weighted images or the FLAIR image. These confluent or multiple punctate hyperintensities are known as white matter lesions (WMLs), which are seen in the deep or perivascular white matter. WMLs are common in the general population, reaching approximately $10 \%$ in the fourth decade of life [9], but their prevalence in patients with migraine is higher and reaches up to $40 \%[8,12]$. While some authors deny the correlation between migraine and WML, others suggest that disorders leading to migraine may also be responsible for microstructural changes and microangiopathy [1]. Although the aetiology of WML is unclear, one possible explanation for their presence is ischaemic damage caused by prolonged hypoper- fusion during a migraine attack [3]. There are some speculations that in migraineurs, blood vessels may show primary or secondary structural abnormalities to migraine, and therefore migraine may be a mirror of the vessel wall state [2]. To verify this hypothesis, we performed an ultrastructural assessment of vessels in migraineurs.

\section{Material and methods}

The study group consisted of 40 patients with migraine and hyperintense white matter changes in MRI scans (Fig. 1) but without risk factors for cerebral vascular diseases such as hypertension, diabetes, and dyslipidaemia. The group consisted of 30 women and 10 men aged 8-58 years (mean age 41). In the examined cases, 24 patients had only migraine (group 1 - isolated migraine). Group 2, called "migraine plus", consisted of 16 patients who, in addition to the migraine, later developed other comorbidities such as transient ischaemic attacks, dementia, epilepsy, or various neurological deficits. The clinical characteristics of the examined population are presented in Table I.

Migraine was diagnosed according to the International Headache Society criteria based on the $3^{\text {rd }}$ beta [22] and verified in the $3^{\text {rd }}$ edition from 2018 [23]. The duration of the disease ranged between 1 and 33 years. The frequency of migraine attacks ranged from 1 attack per week to 1 attack per 6 months (mean frequency 1 attack per month). All patients underwent routine brain MRI, which

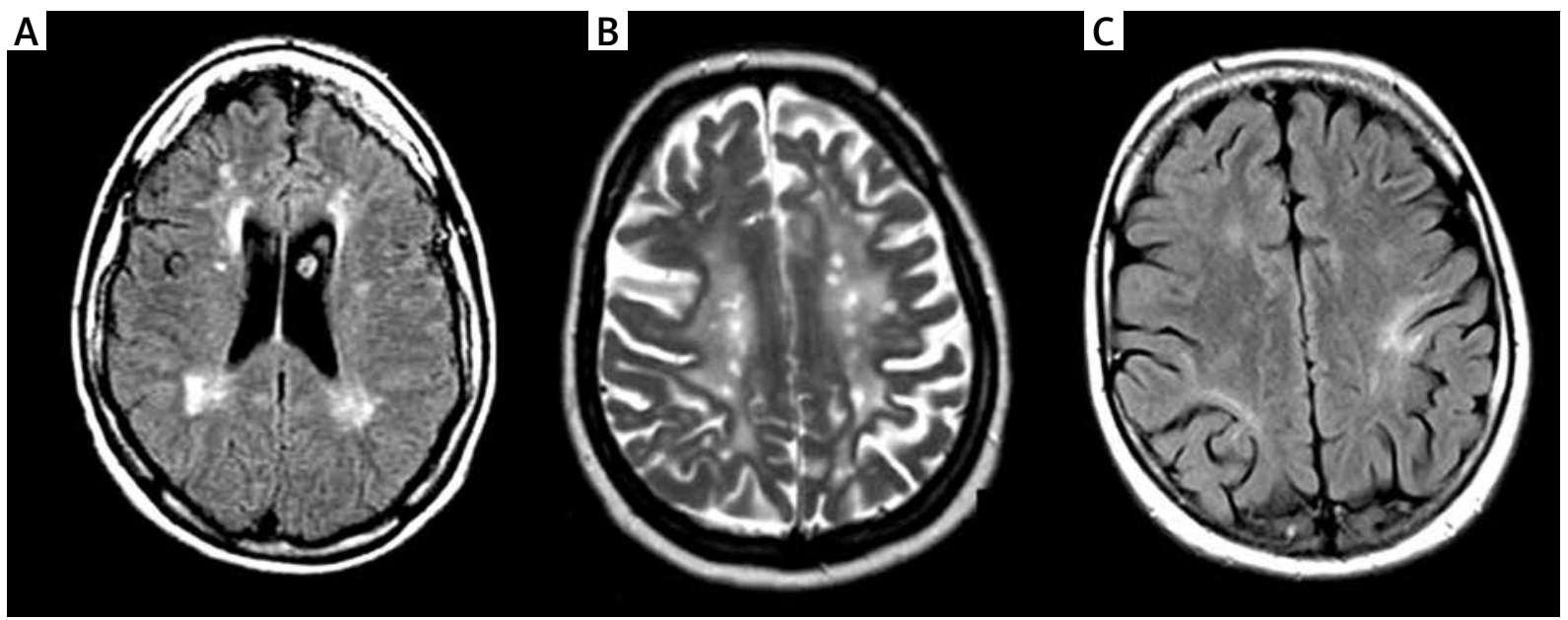

Fig. 1. Different types of hyperintense changes in the cerebral white matter on MRI. A) Periventricular hyperintensities, patient No. 27, B) scattered round foci on a background of confluent white matter hyperintensities, patient No. 6, C) subcortical festoon-like strong signal, patient No. 22. 
Table I. Clinical and ultrastructural characteristics of the studied material

\begin{tabular}{|c|c|c|c|}
\hline \multicolumn{4}{|c|}{ Group 1: Isolated migraine } \\
\hline No. & Sex/age & Main microvasc & ar ultrastructural changes \\
\hline 1 & $F / 37$ & \multicolumn{2}{|c|}{ Characteristic of CADASIL } \\
\hline 2 & $\mathrm{~F} / 27$ & \multicolumn{2}{|c|}{ swelling of endothelial cells } \\
\hline 3 & $M / 34$ & Thickened multilayer basal lamina, endo & nelial activation, narrow and irregular vessel lumen \\
\hline 4 & $\mathrm{~F} / 38$ & \multicolumn{2}{|c|}{ Thickened basal lamina } \\
\hline 5 & $\mathrm{~F} / 58$ & \multicolumn{2}{|c|}{ Elastinopathy (dark deposits within elastin), thickened multilayer basal lamina } \\
\hline 6 & $\mathrm{~F} / 39$ & \multicolumn{2}{|c|}{ Elastinopathy (lack of elastin) } \\
\hline 7 & $F / 24$ & \multicolumn{2}{|c|}{ Elastinopathy (dark deposits within elastin) } \\
\hline 8 & $F / 36$ & \multicolumn{2}{|c|}{ Elastinopathy (dark deposits within elastin), atypical lobular endothelial nuclei } \\
\hline 9 & $\mathrm{~F} / 46$ & \multicolumn{2}{|c|}{ Swelling of endothelial cells and pericytes, extracellular vesicular structures } \\
\hline 10 & $\mathrm{~F} / 31$ & \multicolumn{2}{|c|}{ Swelling of endothelial cells and pericytes, extracellular vesicular structures } \\
\hline 11 & $\mathrm{~F} / 58$ & \multicolumn{2}{|c|}{$\begin{array}{l}\text { Swelling of endothelial cells and pericytes, endothelial activation, narrow and irregular vessel lumen, } \\
\text { intracellular deposits of osmiophilic compact material }\end{array}$} \\
\hline 12 & $\mathrm{~F} / 42$ & \multicolumn{2}{|c|}{$\begin{array}{l}\text { Swelling of endothelial cells and pericytes, endothelial activation, narrow and irregular vessel lumen, } \\
\text { intracellular deposits of osmiophilic compact material }\end{array}$} \\
\hline 13 & $F / 56$ & Endothelial activation, narrow and irreg & lar vessel lumen, intracellular opalizing inclusions \\
\hline 14 & $F / 29$ & \multicolumn{2}{|c|}{ Endothelial activation } \\
\hline 15 & $M / 52$ & \multicolumn{2}{|c|}{ Endothelial activation } \\
\hline 16 & $\mathrm{~F} / 57$ & \multicolumn{2}{|c|}{ Endothelial activation } \\
\hline 17 & $\mathrm{~F} / 46$ & \multicolumn{2}{|c|}{ Narrow and irregular vessel lumen } \\
\hline 18 & $\mathrm{~F} / 45$ & \multicolumn{2}{|c|}{ Deposits of osmiophilic material in VSMC, extracellular vesicular structures and vacuoles } \\
\hline 19 & $\mathrm{~F} / 35$ & \multicolumn{2}{|r|}{ Normal } \\
\hline 20 & $F / 38$ & \multicolumn{2}{|r|}{ Normal } \\
\hline 21 & $F / 29$ & \multicolumn{2}{|r|}{ Normal } \\
\hline 22 & F/46 & \multicolumn{2}{|r|}{ Normal } \\
\hline 23 & $\mathrm{~F} / 25$ & \multicolumn{2}{|r|}{ Normal } \\
\hline 24 & $M / 29$ & \multicolumn{2}{|r|}{ Normal } \\
\hline \multicolumn{4}{|c|}{ Group 2: Migraine plus } \\
\hline No. & Sex/age & Additional symptoms and signs & Main microvascular ultrastructural changes \\
\hline 25 & $M / 57$ & Progressing dementia, Babinski sign & Characteristic of CADASIL \\
\hline 26 & $\mathrm{~F} / 42$ & TIA & Characteristic of CADASIL \\
\hline 27 & $M / 54$ & Since 50 y.o. progressing dementia & Characteristic of CADASIL \\
\hline 28 & $M / 57$ & Pyramidal-extrapyramidal syndrome & Characteristic of CADASIL \\
\hline 29 & $M / 8$ & FHM, epilepsy & Severe, oncosis-like cell swelling \\
\hline 30 & $M / 36$ & FHM & Severe, oncosis-like cell swelling \\
\hline 31 & $M / 46$ & Memory disturbances & Swelling of endothelial cells and pericytes \\
\hline 32 & $\mathrm{~F} / 45$ & TIA & Endothelial cell swelling, intracellular opalizing inclusions \\
\hline 33 & $F / 34$ & Epilepsy & Endothelial activation, intracellular opalizing inclusions \\
\hline 34 & $\mathrm{~F} / 43$ & Epilepsy & $\begin{array}{l}\text { Endothelial activation, bright VSMC, extracellular } \\
\text { vesicular structures and vacuoles }\end{array}$ \\
\hline 35 & $F / 36$ & $\begin{array}{l}\text { Subjective memory problems, } \\
\text { psychoneurological tests normal }\end{array}$ & $\begin{array}{l}\text { Swelling of endothelial cells and pericytes, intracellular } \\
\text { osmiophilic compact deposits }\end{array}$ \\
\hline 36 & $F / 53$ & Depression & $\begin{array}{l}\text { Cell swelling, narrow and irregular vessel lumen } \\
\text { endothelial activation }\end{array}$ \\
\hline 37 & F/48 & $\begin{array}{l}\text { Depressive-delusional syndrome, progressive } \\
\text { spastic tetraparesis }\end{array}$ & $\begin{array}{l}\text { Endothelial activation, enlarged mitochondria, } \\
\text { cytoplasmic vacuoles in pericytes and VSMC }\end{array}$ \\
\hline 38 & $F / 54$ & Brisk right tendon reflexes, right Babinski sign & $\begin{array}{l}\text { Enlarged mitochondria, cytoplasmic vacuoles } \\
\text { in endothelial cells and pericytes }\end{array}$ \\
\hline 39 & $M / 38$ & $\begin{array}{l}\text { Ischaemic stroke at the age of } 35 \text { years } \\
\text { (persistent foramen ovale) }\end{array}$ & Normal \\
\hline 40 & $F / 32$ & Minimal left pyramidal syndrome & Normal \\
\hline
\end{tabular}

FHM - familial hemiplegic migraine, TIA - transient ischaemic attack, VSMC - vascular smooth muscle cell 
revealed an increased signal in the cerebral white matter. Echocardiography and Doppler ultrasound examination of the carotid and vertebral arteries were performed to rule out cardioembolic causes of these hyperintensities. Skin and muscle biopsy was performed in the studied patients due to suspected vasculitis or CADASIL. Tissue samples were prepared for ultrastructural examination according to routine procedures, and they were assessed using a Jeol 1400 Plus electron microscope.

The control group consisted of 20 skin and muscle biopsies from age-matched patients with suspected myopathy and without typical risk factors for cerebrovascular diseases.

\section{Results}

In 32/40 patients $(80 \%)(p<0.005)$ ultrastructural examination revealed various pathological changes in microvessels (Table I) (Fig. 2).

In 5 cases, changes characteristic of CADASIL were found (Fig. 3A). In these patients, microvessels revealed degeneration and loss of pericytes or vascular smooth muscle cells, as well as deposits of granular osmiophilic material (GOM), which were pathognomonic for the disease, in the vascular media or basal lamina. In all patients with an ultra-

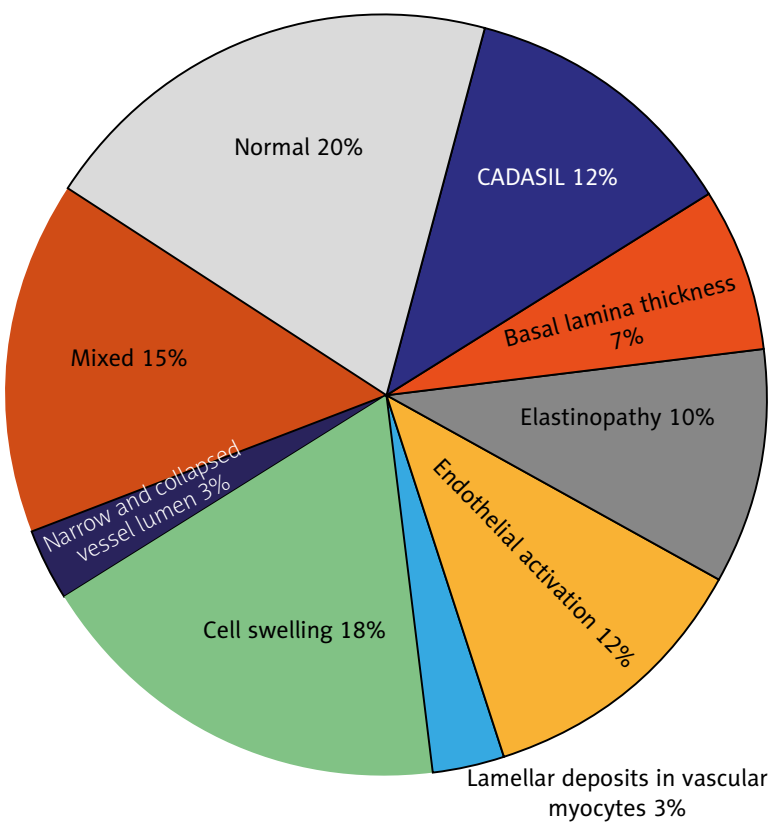

Fig. 2. The prevalence of different types of microangiopathies in the studied material $(n=40)$. structural picture characteristic of CADASIL, genetic tests confirmed the diagnosis.

In the remaining 27 patients with ultrastructural microvessel abnormalities, the pathological changes were not pathognomonic for any currently known angiopathy. The most commonly observed extracellular pathological changes were vesicular structures (Fig. 3B) or vacuoles (Fig. 3C) in the extracellular matrix. In 6 patients, microvessels showed only irregular shape and collapsed vessel lumen (Fig. 3D). In 3 cases the basal lamina was thickened (Fig. 3E, F), and additionally in 2 of them multiplication of its layers was seen. These changes were visible in both small arteries (Fig. 3G) and capillaries (Fig. 3H). In 3 patients isomorphic osmiophilic deposits located below the endothelial cells within elastin were noted (Fig. 3l, J), and in 1 case instead of elastin a homogenous lucent material was visible (Fig. 3K, L).

Ultrastructural abnormalities were also observed in the vessel wall cells. Endothelial activation was seen in 11 cases. Such cells showed an increased number and length of filopodia projecting into the lumen of the vessel and often constricting it (Fig. 4A, B, F). Frequently, erythrocytes adjacent to filipodia (Fig. 4B) or paramural accumulation of platelets were found in microvessel lumen (Fig. 4C). Endothelial cells often had atypical lobular nuclei (Fig. 4E, L). Swelling of the cells, sometimes so severe that it resembled oncosis, was observed in 11 patients. In 7 cases it was the only ultrastructural abnormality, while in 4 cases it coexisted with other vascular pathological changes. Swollen endothelial cells (Fig. 4D, E), enlarged pericytes, pale cytoplasm with numerous vacuoles or multivesicular structures, and enlarged mitochondria were observed. Sometimes, the cytoplasm of such cells contained no intracellular organelles, or they were only single. Swollen endothelial cells often narrowed or even completely occluded the lumen of the microvessels (Fig. 4E).

Numerous vacuoles, sometimes very large and with granular material inside (Fig. 4F,G), as well as round opalescent homogeneous inclusions (Fig. $4 \mathrm{H}, \mathrm{I}$ ) and isomorphic deposits of dark osmiophilic material (Fig. 4J, K), were observed in the extracellular matrix and in cytoplasm of all types of vessel wall cells. In one case, deposits of osmiophilic material in vascular myocytes had a different appearance than in the others: they were more regular in shape and lighter in colour, less compacted or grainy, and with 

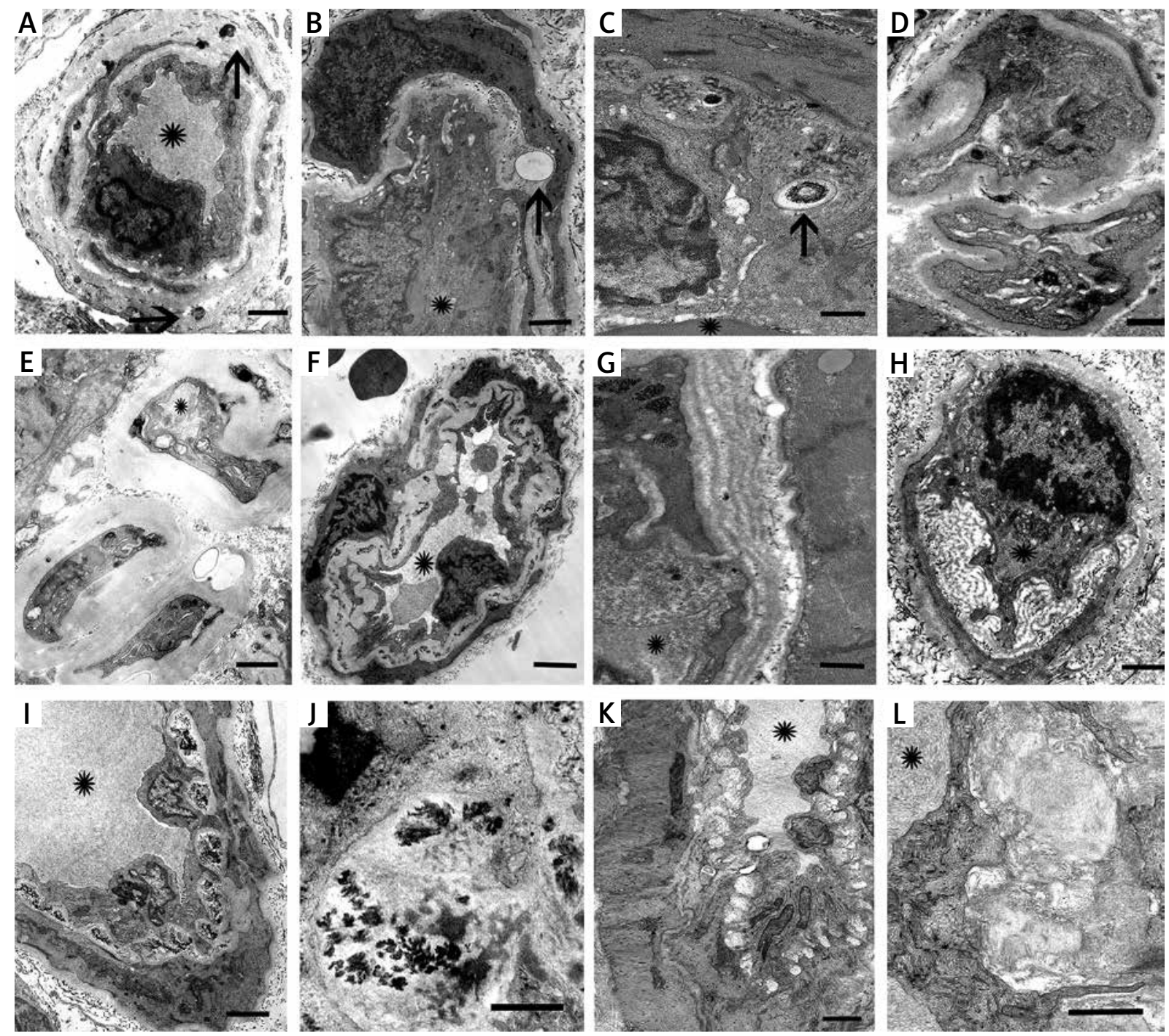

Fig. 3. Ultrastructural changes in vessel wall; asterisk marks vessel lumen. A) CADASIL - degeneration of pericytes, thinned basal lamina, and pathognomonic GOM deposits (arrows) in capillary vessel; patient No. 1; bar $500 \mathrm{~nm}$. B, C) Various types of huge vesicular structures (arrows) in the basal lamina of skin arterioles. Some vacuoles contain calcium deposits (C). B - patient No. 34, C - patient No. 18; bar $500 \mathrm{~nm}$. D) Irregular shape and "collapsing" of the capillary vessel lumen; patient No. 36; bar $500 \mathrm{~nm}$. E) Three capillaries with thickened basal lamina; patient No. 4; bar $500 \mathrm{~nm}$. F) Skin arteriole with thickened basal lamina and deposits of osmiophilic grainy material inside it; patient No. 3; bar $500 \mathrm{~nm}$. G, H) Multiplication of the basal lamina layers in the thickened arteriole (G - patient No. 2; bar $200 \mathrm{~nm}$ ) and capillary vessel $(\mathrm{H}$ - patient No. 3; bar $500 \mathrm{~nm}$ ). I-L) Elastinopathy; isomorphic osmiophilic deposits within elastin in skin small artery (patient No. 7; I- bar $1 \mu \mathrm{m} ;$ J - bar $100 \mathrm{~nm}$ ); lucent homogenous material in location of elastin in skin small artery (patient No. 6; K-bar $1 \mu \mathrm{m} ; \mathrm{L}-$ bar $100 \mathrm{~nm}$ ).

lamellae along their periphery (Fig. 4M). Enlarged mitochondria, often without cristae, and mitochondrial conglomerates were often seen in endothelial cells, pericytes, and vascular smooth muscle cells (Fig. 4N, O).

\section{Discussion}

Our study revealed frequent coexistence of migraine and microangiopathies. Linkage and genetics studies to date have identified genomic regions, 

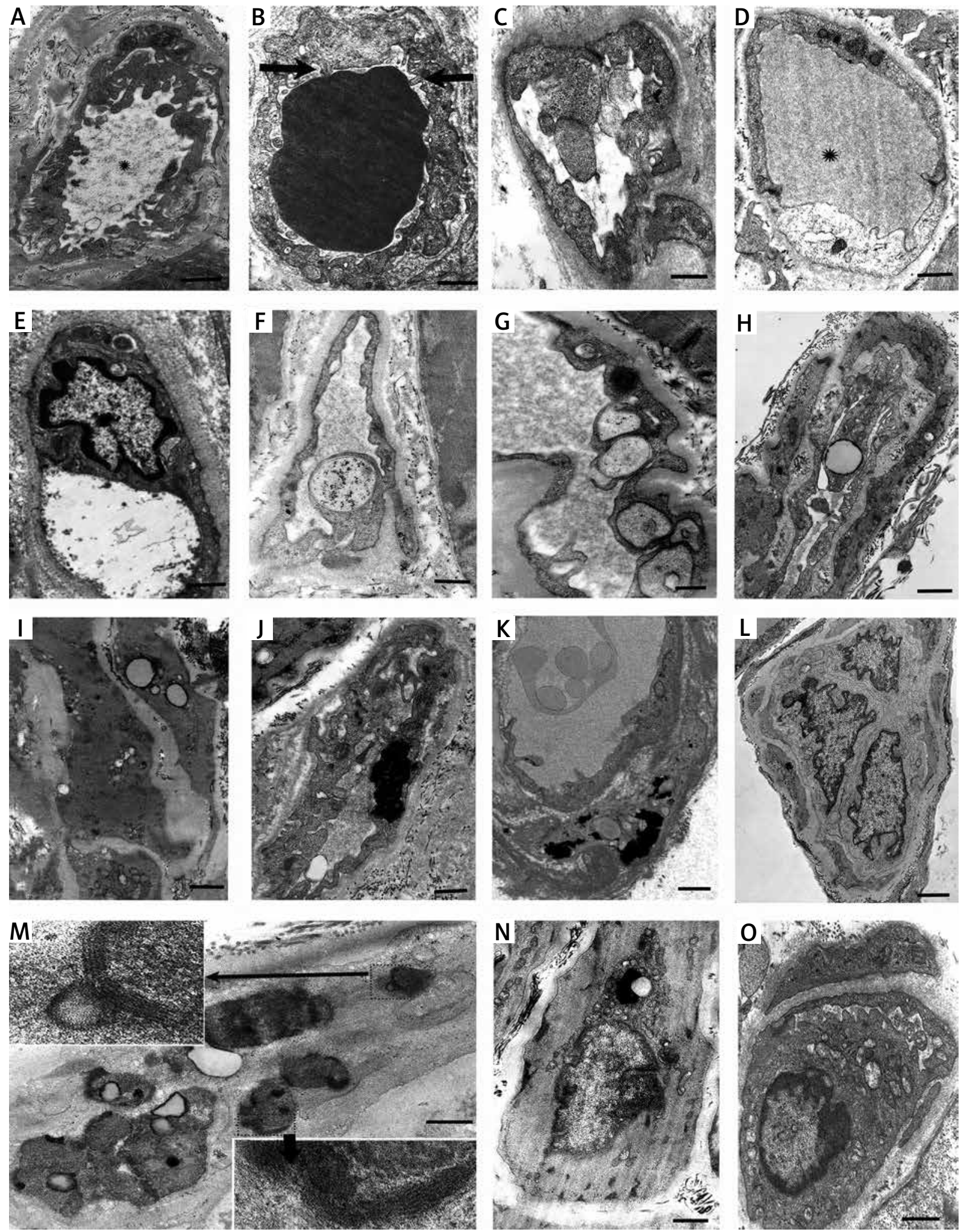

Fig. 4. Ultrastructural changes in vessel wall cells. A) Activated endothelial cells with an increased number and length of filopodia extending into the lumen of the capillary vessel; patient No. 14; bar $500 \mathrm{~nm}$. B) Erythrocyte adjacent to the filopodia of activated endothelial cells (arrows); patient No. 14; bar $500 \mathrm{~nm}$. C) Paramural accumulation of platelets in a capillary vessel with activated endothelium; patient No. 15; bar $500 \mathrm{~nm}$. D) Swollen endothelial cell with pale cytoplasm containing vesicular structures and enlarged reticular cisterns; patient No. 32; bar $500 \mathrm{~nm}$. E) Capillary vessel with lobulated endothelial nucleus and extremely swollen endothelial cell occluding its lumen; patient No. 29; bar 500 nm. F, G) Huge vacuoles with granular material in endothelial cells of skeletal muscle capillary vessel (F) and arteriole (G); patient No. 10; bar $500 \mathrm{~nm}$. H, I) Round homogenous opalizing inclusions in the endothelial (H) and vascular smooth muscle (I) cells; patient No. 33; bar $500 \mathrm{~nm}$. J, K) Isomorphic deposits of osmiophilic compact material in the endothelial (J - patient No. 11) and vascular smooth muscle (K - patient No. 12) cells; bar $500 \mathrm{~nm}$. L) Bizarre lobulated endothelial nuclei invading into and occluding the vessel lumen; patient No. 8; bar $500 \mathrm{~nm}$. M) Oval deposits of grainy material with peripherally located lamellar structures (inserts) in vascular smooth muscle cell; patient No. 18; bar $200 \mathrm{~nm}$. $\mathrm{N}, 0$ ) Clusters of enlarged mitochondria in pericyte $(\mathrm{N})$ and endothelial cell of skeletal muscle capillary vessel; patient No. 38; bar $500 \mathrm{~nm}$. 
and in some cases even genes that are responsible for, or potentially related to, migraine [20,21]. Therefore, if genetic factors can determine the presence of migraine, there can also be genetically conditioned biochemical mechanisms or structural disorders responsible for the occurrence of migraine. Especially in the latter case, migraine ceases to be a separate disease and becomes a symptom of angiopathy.

When assessing the vessels, we found ultrastructural changes that allowed us to identify specific microangiopathies such as CADASIL, but in most cases, vascular abnormalities were not attributed to any currently known disease. One such ultrastructural change was the isolated thickening of the basal lamina. The presence of the thickened basal lamina suggests disturbances in compounds of the extracellular matrix. It is possible that this group of patients will be diagnosed with collagenopathy, lamininopathy, or some other type of "matrixopathy" in the future. Also, the presence of irregular osmophilic deposits with lamellar structures in myocytes seems to be a relatively characteristic abnormality that may allow the detection of a new microangiopathies in the future. Another characteristic ultrastructural disorder we observed was loss of normal elastin and the presence of dark or lucent isomorphic deposits in the vessel wall. These findings indicate that elastinopathy may be present in some migraineurs.

However, most migraine sufferers have seen non-specific ultrastructural changes in the vessels such as endothelial activation, pathological mitochondrial accumulation, and cell swelling. These non-characteristic specific changes are probably secondary to other biochemical or functional disturbances. Some of these non-specific abnormalities seem to be the pathomechanism of a particular disorder. In 2 related patients from group 2 with familial hemiplegic migraine with CACNA1A mutation (FHM1), the cell swelling was so severe that it resembled oncosis. In oncosis, deregulation of calcium currents is responsible for increased calcium concentration in the cell, water influx, and cellular swelling preceding cell death [24]. In FHM1, CACNA1A mutations change the structure of CaV2.1 calcium channels, which open more easily [19], and which in turn can lead to oncotic changes in cells [7]. However, these potential pathogenetic relationships do not contradict the non-specific nature of cell oedema and oncosis-like lesions in other disorders. In mitochondriopathies, for example, energy deficiency can manifest morphologically not only as an increased number of enlarged or aggregated mitochondria, but also as swelling of vascular wall cells.

Mitochondriopathies are also important for another reason. In mitochondrial diseases, microangiopathy may manifest clinically as migraine-like headache, leukoencephalopathy, stroke-like episodes, or peripheral retinopathy, or may remain subclinical and manifest only as the above-mentioned morphological abnormalities in vessel wall cells [6]. However, in a retrospective analysis, it was found that migraine is common also in such non-symptomatic patients with mitochondrial microangiopathy [11], and some authors even suggest that aberrations in the mitochondrial DNA may contribute to the pathogenesis of migraine [13].

Recognition of microangiopathy in a group of patients with migraine raises the question whether the clinical diagnosis of migraine is correct. Perhaps, in such patients, it would be better to diagnose migraine-like headaches instead of migraine. However, re-diagnosis is impossible without the results of a morphological examination of the vessels. Identification of patients with migraine/migraine-like headaches and coexisting microangiopathy is important from a practical point of view. Studies showed that migraine is associated with an increased risk of cerebrovascular diseases $[16,17]$, and may be regarded as an early marker of some diseases like hereditary cerebral amyloid angiopathy, in which migraine precedes the occurrence of other clinical symptoms by several years [15]. Migraine, particularly migraine with aura, is also associated with an increased risk of cardiovascular events [5,16], and one of the plausible mechanisms predisposing individuals with migraine to vascular disease is dysfunction of peripheral arterial vessels [14]. If migraine itself is associated with an increased risk of cardio-cerebral vascular disease, then migraine with microangiopathy increases the risk even more. The question arises whether the abovementioned vessel abnormalities observed in our patients can be markers capable of identifying patients with migraine who are more prone to vascular events, and how specific and sensitive these markers are. Answers to these questions require further investigation.

In summary, migraineurs should be carefully evaluated considering their vascular risk assessment. Our research has shown that skin and muscle biopsy can quickly identify microangiopathy in migraineurs. 
Isolation of the group of patients with concomitant migraine and microangiopathy is of great clinical significance because the risk of ischaemic stroke and other vascular diseases is higher in this group than for migraine alone. Perhaps this group of patients should be the target of special therapies and other preventive strategies that would prevent vascular brain damage.

\section{Statement of ethics}

The study was approved by the Ethics Committee of the Medical University of Warsaw AKBE/165/17 in accordance with the Helsinki Declaration, and all participants signed a written consent form to participate in the study.

\section{Funding}

This research did not receive any specific grants from funding agencies in the public, commercial, or not-for-profit sectors.

\section{Disclosure}

The authors report no conflict of interest.

\section{References}

1. Arkink EB, Palm-Meanders IH, Koppen H Milles J, van Lew B, Launer LJ, Hofman PAM, Terwindt GM, van Buchem MA, Ferrari MD, Kruit MC. Microstructural white matter changes preceding white matter hyperintensities in migraine. Neurology 2019; 93: 688-694.

2. Bednarczyk C. Is migraine a mirror of the vessel wall? Neurology 2010; 75: 946-947.

3. Bednarczyk EM, Remier B, Weikart C, Nelson AD, Reed RC. Global cerebral blood flow, blood volume, and oxygen metabolism in patients with migraine headache. Neurology 1998; 50: 17361740.

4. Bigal ME, Kurth T, Santanello N, Buse D, Golden W, Robbins M, Lipton RB. Migraine and cardiovascular disease: a population-based study. Neurology 2010; 74: 628-635.

5. Brunner H, Cockcroft JR, Deanfield J, Donald A, Ferrannini E, Halcox J, Kiowski W, Lüscher TF, Mancia G, Natali A, Oliver J,, Pessina AC, Rizzoni D, Rossi GP, Salvetti A, Spieker LE, Taddei S, Webb DJ. Endothelial function and dysfunction. Part II: Association with cardiovascular risk factors and diseases. A statement by the Working Group on Endothelins and Endothelial Factors of the European Society of Hypertension. J Hypertens 2005; 23: 233-246.

6. Coquet M, Fontan D, Vital C, Tudesq N, Baronnet R. Muscle and brain biopsy in a case of mitochondrial encephalomyopathy. Ann Pathol 1990; 10: 181-186.
7. Dziewulska D, Kierdaszuk B. Ultrastructural changes in microvessels in familial hemiplegic migraine with CACNA1 mutation. Clin Neuropathol 2018; 37: 283-287.

8. Fazekas F, Koch M, Schmidt R, Offenbacher H, Payer F, Freidl $W$, Lechner $H$. The prevalence of cerebral damage varies with migraine type: a MRI study. Headache 1992; 32: 287-291.

9. Fazekas F. Magnetic resonance signal abnormalities in asymptomatic individuals: their incidence and functional correlates. Eur Neurol 1989; 29: 164-168.

10. Finsterer J, Scorza CA, Scorza FA, Wakil SM. Update on hereditary, autosomal dominant cathepsin A related arteriopathy with strokes and leukoencephalopathy (CARASAL). Acta Neurolog Belg 2019; 119: 299-303.

11. Finsterer J, Zarrouk-Mahjoub S. Mitochondrial vasculopathy. World J Cardiol 2016; 8: 333-339.

12. Gozke E, Ore O, Dortcan N, Unal Z, Cetinkaya M. Cranial magnetic resonance imaging findings in patients with migraine. Headache 2004; 44: 166-169.

13. Guo S, Esserlind AL, Andersson Z, Frederiksen AL, Olesen J, Vissing J, Ashina M. Prevalence of migraine in persons with the 3243A>G mutation in mitochondrial DNA. Eur J Neurol 2016; 23: $175-181$.

14. Koemans EA, Voigt S, Rasing I, van Etten ES, van Zwet EW, van Walderveen MAA, Wermer MJH, Terwindt GM. Migraine with aura as early disease marker in hereditary Dutch-type cerebral amyloid angiopathy. Stroke 2020; 51: 1094-1099.

15. Kurth T, Rist PM, Ridker PM, Kotler G, Bubes V, Buring JE. Association of migraine with aura and other risk factors with incident cardiovascular disease in women. JAMA 2020; 323: 2281-2289.

16. Mahmoud AN, Mentias A, Elgendy AY, Qazi A, Barakat AF, Saad M, Mohsen A, Abuzaid A, Mansoor H, Mojadidi MK, Elgendy IY. Migraine and the risk of cardiovascular and cerebrovascular events: a meta-analysis of 16 cohort studies including 1152407 subjects. BMJ Open 2018; 8: e020498.

17. Øie LR, Kurth T, Gulati S, Dodick DW. Migraine and risk of stroke. J Neurol Neurosurg Psych 2020; 91: 593-604.

18. Pantoni L. Cerebral small vessel disease: from pathogenesis and clinical characteristics to therapeutic challenges. Lancet Neurol 2010; 9: 689-701.

19. Pietrobon D. Cortical spreading depression and familial hemiplegic migraine. J Headache Pain 2015; 16 (Suppl 1): A20.

20. Sathe S. Migraine and neurogenetic disorders. Curr Pain Headache Rep 2013; 17: 360.

21. Stam AH, Haan J, van den Maagdenberg AM, Ferrari MD, Terwindt GM. Migraine and genetic and acquired vasculopathies. Cephalalgia 2009; 29: 1006-1017.

22. The International Classification of Headache Disorders, $3^{\text {rd }}$ edition (beta version). Cephalalgia 2013; 33: 644-658.

23. The International Classification of Headache Disorders 3rd edition. Cephalalgia 2018; 38: 1-211.

24. Weerasinghe P, Buja LM. Oncosis: an important non-apoptotic mode of cell death. Exp Mol Pathol 2012; 93: 302-308. 